\title{
ENTREVISTA COM VANISE MEDEIROS
}

\author{
INTERVIEW WITH VANISE MEDEIROS
}

\author{
Vanise Medeiros ${ }^{1}$, Rívia Silveira Fonseca ${ }^{2}$ \\ ${ }^{1}$ Universidade Federal Fluminense (UFF), Niterói, RJ, Brasil \\ vanisegm@yahoo.com.br \\ ${ }^{2}$ Universidade Federal Rural do Rio de Janeiro (UFRRJ), Seropédica, RJ, Brasil \\ riviafonseca@gmail.com
}

Entrevista concedida em 16 dez. 2019

Rívia Fonseca - Antes de trabalhar no Departamento de Ciências da Linguagem na UFF, como professora de linguística, você trabalhou em diferentes níveis de ensino como professora de língua portuguesa. Especificamente, desenvolveu pesquisas na área de descrição do português e ensino de língua portuguesa. Em que momento e de que maneira os estudos em Análise do Discurso atravessaram a sua relação com o ensino de língua?

Vanise Medeiros - Os estudos em Análise de Discurso sempre atravessaram o meu trabalho, fosse ele qual fosse.

Fui afetada pela teoria ainda na graduação que fiz na PUC. Como narro em Habitar uma teoria, artigo escrito com Bethania Mariani e Tatiana Moura (2011, p. 296) ${ }^{1}$, numa aula de fonologia, ministrada por Bethania, uma palavra no quadro com parênteses liberando sentidos outros me fez perceber algo na língua que me surpreendeu de modo irremediável. Não era a língua das aulas de linguística; não era a língua dos estudos gramaticais. Era algo que eu entrevia na literatura e que, naquela aula, descobri que poderia investigar com prazer na Análise de Discurso. Um mistério se pôs a me fascinar e ainda me fascina.

Como você disse, dei aula de descrição do português e ensino de língua portuguesa e o que embasava minhas aulas, mesmo sem eu ter projetado teoricamente, era tal teoria. Por exemplo, em minhas atividades para aula de português para estrangeiro, eu não trabalhava a língua como se fosse algo descolado da condição de sujeito. Eu considerava os (des)encontros, a tensão na língua; sabia que os sentidos não estavam colados às palavras, que não eram mudanças de rótulos com implicações no comportamento que deveriam aprender. Em uma palavra, estava em jogo nas aulas a opacidade da linguagem.

\footnotetext{
${ }^{1}$ MARIANI, B.; MOURA, T. F.; MEDEIROS, V. Habitar uma teoria. In: RODRIGUES, E. A.; SANTOS, G. L. dos; CASTELLO BRANCO, L. K. (org.). Análise de Discurso no Brasil: uma homenagem a Eni Orlandi. Campinas: RG editores, 2001. p. 293-310.
} 
Um outro exemplo seria de minhas aulas de sintaxe I, um dos cursos que ministrei quando professora da UERJ. Eu levava para as aulas definições de cada função sintática em ao menos cinco consagradas gramáticas para compará-las com os alunos. E acrescentava, em sala, definições de gramáticas anteriores à NGB. Trabalhava, assim, a leitura de tais gramáticas, ou seja, ia mostrando as posições discursivas, a memória incidindo nas definições, as rupturas, os apagamentos, os silêncios. Eu não usava esta terminologia com os alunos, mas ela fazia parte da leitura. Eu analisava com os alunos os caminhos de cada gramática, os embates que advinham das tomadas de posição, as contradições. Por um lado, isto colocava em suspensão os engessamentos do saber; por outro lado, permitia observar como saberes iam ou não se configurando e se tornando evidências.

Naquele início de UERJ, eu ainda não fazia pesquisa no campo da História das Ideias Linguísticas (HIL), mas naquelas aulas já colocava foco nos instrumentos linguísticos. É preciso dizer também que eu já era leitora dos textos e livros de Orlandi $(2002,2001)^{2}$ com a HIL e, por conseguinte, do livro de Auroux (1992) ${ }^{3}$, e já tinha um primeiro grupo de estudos, formado por alunos da graduação, em que estudávamos Análise de Discurso. Foram as aulas na UERJ, o grupo de estudos e os alunos que me levaram a montar meu primeiro projeto de Iniciação Científica, já em Análise de Discurso/História das Ideias Linguísticas.

R. F. - Efeitos de sentidos produzidos pelos gestos de interpretação de determinadas expressões como "língua nacional", língua estrangeira", "língua materna", pensando-se em sua relação com o significante "língua portuguesa", circulam dentro e fora da escola. E, dentro da escola, esses sintagmas se associam para materializar os sentidos de uma "língua de Estado" que deve ser ensinada e, consequentemente, deve ter o seu uso "correto" medido por parâmetros estabelecidos pelas instituições controladas pelo próprio Estado. Como é possível ao professor de língua portuguesa, de uma perspectiva materialista da linguagem, como propõe a Análise do Discurso, lidar com os mecanismos externos de avaliação institucionalizados e, ao mesmo tempo, avaliar o desenvolvimento do aluno como sujeito da e na língua?

V. M. - Suas perguntas são maravilhosas e difíceis ao mesmo tempo, porque expõem os problemas que temos como professor em sala de aula de língua portuguesa. Para mim, sempre foi, e ainda é, deveras estimulante provocar o aluno a pensar sobre estes rótulos. Sempre acho apaixonante perceber como algo

\footnotetext{
${ }^{2}$ ORLANDI, E. Língua e conhecimento linguístico: para uma História das Idéias no Brasil. São Paulo: Cortes, 2002.

ORLANDI, E. (org.). História das idéias políticas: construção do saber metalinguístico e constituição de língua nacional. Campinas: Pontes; Cáceres: UNEMAT, 2001.

${ }^{3}$ AUROUX, S. A revolução tecnológica da gramatização. Campinas: Unicamp, 1992.
} 
incomoda ou sai de lugar quando perguntamos o que vem a ser língua portuguesa e por que se chama língua portuguesa e não língua brasileira, o que vem a ser língua nacional, língua materna, que língua eles falam, qual a relação da língua com a nação e com aquele que fala, por que as partições por regiões e por estados, como se constroem essas fronteiras em um país, e por aí vai... As perguntas não se esgotam; tampouco as respostas. Dar aula de língua é, para mim, situar-se num espaço tenso, móvel, cambiante, cuja estabilidade parece residir em rótulos, mas que, uma vez questionados, permitem emergir uma série de outras questões que iluminam a relação entre língua em sujeito. É este o fascínio no ensino de língua para mim.

Sua pergunta me remete ainda para duas noções que considero importantíssimas para o trabalho com língua: são as noções de língua imaginária e de língua fluida (ORLANDI, 1990) ${ }^{4}$ na medida em que possibilitam compreender língua em seu funcionamento: a primeira, sinalizando para um imaginário de língua que se supõe um sistema contornado e contido pelas gramáticas; a segunda, denunciando a ilusão dessa língua sistema, isto é, a segunda nos permite observar que os contornos não são fixos, que não dão conta da potência da língua, que a língua transborda em equívocos e deslizamentos. Em outras palavras, se a primeira nos faz supor um terreno estável ou estabilizado, a outra põe à mostra aquilo que, muitas vezes, como professores(as) de língua, jogamos para debaixo do tapete. Não é tarefa fácil. É luta (e como toda luta, perdemos por vezes) e fascínio diários. Quanto aos mecanismos de avaliação, estes desconhecem não somente tal dimensão da língua, mas, o que é pior, eles operam como mecanismos externos de enquadramento e limitação do sujeito e da língua. Aí a luta é desigual e qualquer pequena vitória já é uma grande vitória.

R. F. - Em A linguagem e seu funcionamento (1996) ${ }^{5}$, ao tratar do discurso pedagógico, com reflexões que foram expostas ainda na década de 80, numa reunião da SBPC, Orlandi registra que, para ela, o discurso pedagógico, "sendo um discurso institucional, reflete relações institucionais das quais faz parte; se essas relações são autoritárias, ele será autoritário. O seu mal raiz é, pois, refletir a ordem social na qual existe. Mas, como essa não é uma relação mecânica, alguma coisa escapa e é sempre possível a crítica." (p. 37) A seu ver, como analista do discurso e como professora de língua e linguística, essa análise se mantém atual quase 40 anos depois? Tomando a cena política do momento, no Brasil, o que se pode

\footnotetext{
${ }^{4}$ ORLANDI, E. Terra à vista! Discurso de confronto: o velho e o novo mundo. São Paulo: Cortez/UNICAMP, 1990.

${ }_{5}$ ORLANDI, E. Para quem é o discurso pedagógico. In: ORLANDI, E. A linguagem e seu funcionamento: as formas do discurso. 4. ed. Campinas: Pontes, 1996. p. 25-38.
} 
esperar do funcionamento do discurso pedagógico? Se há algo que escapa, o que é e como o faz?

V. M. - Esta é uma pergunta por demais complexa. Não sei se vou dar conta de responder aqui. Você me convoca a refletir doravante sobre ela e o que vou responder é o que me é possível no momento. Por um lado, considero o discurso pedagógico não somente como atravessado por um discurso institucional e concordo com Orlandi. Nesse ponto, estou pensando também à luz de Althusser e do que ele traz como aparelhos ideológicos do Estado. No entanto, é preciso lembrar que nossa realidade não é a realidade francesa, lugar a partir do qual ele formula tal conceito. Tampouco a historicidade de nossas instituições escolares é a mesma da europeia. De imediato, nossas escolas públicas não são nacionais e não são para todos, como sabemos. Nossas escolas públicas são também resistência, ainda que micro; significam formas de sobrevivência. Sobretudo, atualmente, diante do estado de coisas que estamos vivendo, isto é, dos atuais momentos de autoritarismo e de declarada guerra ao ensino e aos professores. São guerras que advêm, como a história nos conta, de governos que não suportam nada a não ser a obediência cega que massacra aquele com o qual não se identifica, que instaura uma partição cruel na sociedade entre os que seriam os "nós", que teriam direitos postos como naturais, e o que seriam os "outros", sem direito a nada, sequer à vida para falarmos nos termos de necropolítica (MBEMBE, 2018)

Nesse momento atual, é preciso defender ferreamente as escolas também da língua de vento da propaganda mentirosa e ardilosa que nos assola e que arruína nossas instituições escolares. A língua de vento é mais forte que a língua de ferro, do totalitarismo, nos lembra Pêcheux em $A$ língua inatingível. É vento que tudo destrói, que tudo varre, que nada deixa, que apaga vestígios. E quando a língua de vento se enrosca na língua de madeira, do direito e de uma política autoritária, é preciso a ela fazer resistência. É este o lugar também da escola atualmente. Tenho a impressão de que não respondi exatamente o que me foi perguntado, mas respondi ao que sua pergunta deflagrou em mim nestes tempos mais que sombrios que estamos vivendo.

R. F. - Pêcheux, no livro A língua inatingível $(2004$, p. 55) afirma que "o real da língua não é costurado nas suas margens como uma língua lógica: ele é cortado por falhas, atestadas pela existência do lapso...". Esta é uma noção de língua que não se encontra nos livros didáticos e manuais de língua portuguesa, nem nos glossários

\footnotetext{
${ }^{6}$ MBEMBE, A. Necropolítica. São Paulo: $\mathrm{n}-1$ edições, 2018.

${ }^{7}$ GADET, F.; PECHÊUX, M. Dois Saussure?. In: GADET, F; PÊCHEUX, M. A língua inatingível. O discurso na história da linguística. Campinas: Pontes, 2004. p. 55-61.
} 
e dicionários, objetos de análise em suas pesquisas. Como o professor de língua portuguesa na escola, hoje, poderia mobilizar "a falha", "o equívoco", "o lapso" em atividades de ensino de língua portuguesa, tendo em vista os mecanismos de coerção que regularizam a sua prática em sala de aula?

V. M. - Na sua segunda pergunta, eu já havia assinalado para a língua como sendo também lugar do equívoco, do deslizamento, e, como você lembra, do lapso, da falha. É muito bonito quando os alunos percebem que o lapso, o equívoco, a falha podem ser compreendidos pelo deslizamento de uma letra para outra, de uma palavra por outra. Quando eles percebem que eles produzem lapsos, que tateiam sobre palavras, sobre o dizer e que isto é língua e não algo fora da língua. Este é o mistério fascinante de que falei lá no início. Penso que o trabalho com glossários e dicionários nos ajudam e muito a desfazer o mito de uma língua sem falhas, sem deslizamentos e sem historicidade.

O trabalho em sala de aula com dicionários - impressos ou digitais - é importantíssimo porque eles permitem observar, quando confrontamos diferentes dicionários, como os sentidos são porosos, como não são evidentes, como a forma de definição - a sinonímia, a polissemia, a remissão a outros verbetes, a sintaxe, a indicação de variação, por exemplo - produz sentidos. Trabalhar por exemplo alguns verbetes em sala ilumina aquilo que se diz, aquilo que não se diz, aquilo é interditado ao dizer. Mas não somente. O digital, por exemplo, permite observar as peças que a tecnologia nos prega na medida em que certas remissões ocorrem para uns ao acessar o computador e não para outros, que certas remissões se repetem, que outras nunca ocorrem e por aí vai... E não se trata de acaso. Brincar com dicionários em sala nos garante uma vigorosa reflexão sobre nossa sociedade. É o que nos mostram os trabalhos de Horta Nunes $(2006)^{8}$, de Petri $(2018)^{9}$ e de Freitas $(2019)^{10}$. É o que meus estudos com glossários têm me possibilitado: descortinar um mundo que parece deixado de lado, mas que produz sentidos e não somente nos brasileiros.

R. F. - Em artigo recente, A retórica da mediação: dois momentos ${ }^{11}$, você analisa comparativamente as notas de rodapé dos romances $\mathrm{O}$ Guarani e Iracema, ambos

\footnotetext{
${ }^{8}$ NUNES, J. H. Dicionários no Brasil. Campinas: Pontes Editores; São Paulo: FAPESP; São José do Rio Preto: FAPERP, 2006.

${ }^{9}$ PETRI, V. História de palavras na história das ideias linguísticas: para ensinar língua portuguesa e para desenvolver um projeto de pesquisa. Conexão Letras, Porto Alegre, v. 13, p. 47-58, 2018.

${ }_{10}$ FREITAS, R. A. Efeitos do político na instrumentação da língua pelo Google: uma análise da palavra-chave "governabilidade". In: GRIGOLETTO, E.; DE NARDI, F. S.; SOBRINHO, H. F. Sujeito, Sentido, Resistência: entre a arte e o digital. Campinas: Pontes, 2019. p. 233-248

${ }^{11}$ MEDEIROS, V. A retórica da mediação: dois momentos. Linguagem em (Dis)curso, Tubarão, v. 19 , n. 2, p. 355-371, jul. 2019.
} 
de José de Alencar. E, na conclusão do estudo, afirma: "o movimento de aproximação da língua indígena com a portuguesa não se dá sem o encobrimento da língua indígena." Uma reflexão crítica sobre a relação entre estas línguas não pode acontecer a partir de um quadro teórico que exclua a historicidade das línguas e dos sujeitos. Considerando o seu próprio percurso como pesquisadora na área, que papel uma disciplina voltada para a História das ideias linguísticas poderia ter na formação de professores em nível de graduação ou mesmo em programas de pósgraduação na área de Letras?

V. M. - De imediato, agradeço a leitura dos meus trabalhos, a troca que aqui já se instaura e a resposta, que adorei, com sua leitura: "Uma reflexão crítica sobre a relação entre estas línguas não pode acontecer a partir de um quadro teórico que exclua a historicidade das línguas e dos sujeitos." Pois é, não pode mesmo. Infelizmente, desconhecemos a historicidade da língua e da relação dela com sujeitos. E mesmo nos cursos de graduação! Em geral, é somente por leituras e pesquisas específicas que este mundo se abre. E fica a pergunta: o que mudaria no nosso aprendizado se desde cedo fôssemos levados a saber da historicidade das línguas várias em solo brasileiro? Daí a importância de uma disciplina como a História das ideias Linguísticas nos currículos de graduação. Voltando ao trecho que você traz do meu artigo, ele se trata de um certo movimento, não único, como tento mostrar, que ocorre com os verbetes que se tecem ao pé de página ou ao final dos livros de Alencar. Se, neles línguas indígenas comparecem, seja encabeçando seja na definição, há um movimento que as apaga destes dois lugares. São momentos específicos de semantização de mundo que também me interessam estudar porque são movimentos recorrentes no contato entre línguas, sobretudo quando dicionários e glossários, por exemplo, são escritos a partir de uma língua tida, estudada e considerada como nacional.

Vou tomar ainda um outro caso: o do glossário construído por Júlio Ribeiro para seu livro A Carne, romance contemporâneo aos de Alencar. No glossário de Ribeiro, exposto ao final da primeira edição do livro e composto por mais de quarenta verbetes, encontramos léxico e referências ao "vocabulário africano" ou ainda ao "português dos pretos do Brasil". Um outro universo se abre. Lá temos verbetes que não estão presentes em dicionários anteriores ao livro, como é o caso dos dicionários de Bluteau, Silva Pinto e Moraes Silva, ou seja, lá se dicionarizam termos e expressões de línguas de escravizados. Ler os romances e seus glossários elucidam o modo como essas línguas vão sendo discursivizadas. Mas não somente: eles denunciam outros aspectos, como, por exemplo, a oralidade que vai sendo significada em função do lugar de onde advém, isto é, se nas capitais ou no interior, se no Rio de Janeiro, ou se fora do Rio de Janeiro, para ficar com o confronto entre 
Dialeto Caipira de Amadeu Amaral e O linguajar carioca de Antenor Nascentes, bem como como a variação adentra: se como regional, caso do glossário de Mário Palmério, ou como vocabulário das ruas, caso de João Antonio. Enfim, como já afirmei em outros trabalhos, os glossários, assim como os dicionários, iluminam o modo e o limite de pertencimento de sujeitos e seus dizeres a uma língua. Ler tais materiais me permitiu observar alguns gestos em relação à língua e algumas das contradições que, infelizmente, permanecem em nossa sociedade. É preciso pensar sobre elas; é preciso pensar sobre as relações entre as línguas; é preciso pensar sobre os sujeitos e suas línguas. É esta a dimensão que a História das Ideias Linguísticas enlaçada com a Análise de Discurso nos permite estudar e compreender.

\section{Sobre a entrevistada}

\section{Vanise Medeiros}

Professora associada da UFF, com pós-doutorado pela Sorbonne Nouvelle Paris III, bolsista 2 do CNPq e Cientista do Nosso Estado (FAPERJ). É uma das coordenadoras do Laboratório Arquivos do Sujeito (LAS) da UFF e coordenadora do grupo de pesquisa Arquivos de Língua (GAL). Pesquisa na área de Análise de Discurso e de História das Ideias Linguísticas.

\section{Sobre a entrevistadora}

\section{Rívia Silveira Fonseca}

Licenciada em Letras (1998) e Mestra em História Social (2002) pela Universidade Federal Fluminense - UFF e Doutora em Linguística (2009) pela Universidade Estadual de Campinas UNICAMP. Atualmente, é Professora Associada I, na área de língua e literatura latina, e Chefe do Departamento de Letras e Comunicação - DLC da Universidade Federal Rural do Rio de Janeiro UFRRJ. Faz parte do corpo docente do ProfLetras e desenvolve pesquisas na área dos Estudos da Linguagem, com ênfase em Teoria e Análise Linguística, Estudos do Discurso e Ensino de Línguas. 